\title{
The phosphatase and tensin homologue deleted on chromosome I 0 mediates radiosensitivity in head and neck cancer
}

\section{WJ Pattje ${ }^{1,2}$, E Schuuring ${ }^{2}$, MF Mastik ${ }^{2}$, L Slagter-Menkema ${ }^{1,2,3}$, ML Schrijvers ${ }^{2,3}$, S Alessi $^{4}$, BFAM van der Laan ${ }^{3}$, JLN Roodenburg ${ }^{5}$, JA Langendijk' and JE van der Wal',2}

'Department of Radiation Oncology, University Medical Center Groningen, University of Groningen, Groningen, The Netherlands; ${ }^{2}$ Department of Pathology and Medical Biology (HPC EA I0), University Medical Center Groningen, University of Groningen, PO Box 30.00 I, Groningen 9700 RB, The Netherlands; ${ }^{3}$ Department of Otorhinolaryngology and Head and Neck Surgery, University Medical Center Groningen, University of Groningen, Groningen, The Netherlands; ${ }^{4}$ Sapienza-Università di Roma, Rome, Italy; ${ }^{5}$ Department of Oral and Maxillofacial Surgery, University Medical Center Groningen, University of Groningen, Groningen, The Netherlands

BACKGROUND: For locally advanced squamous cell carcinoma of the head and neck (HNSCC), the recurrence rate after surgery and postoperative radiotherapy is between 20 and $40 \%$, and the 5 -year overall survival rate is $~ 50 \%$. Presently, no markers exist to accurately predict treatment outcome. Expression of proteins in the human epidermal growth factor receptor (EGFR) pathway has been reported as a prognostic marker in several types of cancer.

METHODS: The aim of this study was to investigate the prognostic value of proteins in the EGFR pathway in HNSCC. For this purpose, we collected surgically resected tissue of 140 locally advanced head and neck cancer patients, all treated with surgery and postoperative radiotherapy.

RESULTS: In a multivariate analysis, expression of the phosphatase and tensin homologue deleted on chromosome 10 (PTEN) was significantly related to worse locoregional control (LRC; HR: 2.2, 95\% Cl: I.I -4.6; $P=0.03$ ), independent of lymph node metastases (HR: 5.6, 95\% Cl: 1.2-27.4; $P=0.03$ ) and extranodal spread (HR: 2.7; 95\% Cl: 1.2-6.5; $P=0.02$ ). In vitro clonogenic radiosensitivity assays confirmed that overexpression of PTEN resulted in increased radioresistance.

CONCLUSION: Our study is the first report showing that expression of PTEN mediates radiosensitivity in vitro and that increased expression in advanced HNSCC predicts worse LRC.

British Journal of Cancer (2010) I 02, 1778-1785. doi:I0.1038/sj.bjc.6605707 www.bjcancer.com

Published online 25 May 2010

(c) 2010 Cancer Research UK

Keywords: PTEN; HNSCC; radiosensitivity; locoregional control; EGFR pathway

The prognosis for patients with locally advanced head and neck squamous cell carcinoma (HNSCC) depends on numerous clinical and histopathological factors. Despite intensive curative treatment strategies, such as surgery and postoperative radiotherapy, $20-40 \%$ of all patients will develop a locoregional recurrence (LRR) and the 5-year overall survival rate remains $\sim 50 \%$ (Le Tourneau et al, 2008). For this reason, attempts have been made to identify molecular markers that are able to improve the identification of tumours that will develop LRR and thus might benefit from more aggressive treatment strategies (Partridge et al, 2005). One of the potential prognostic factors is the epidermal growth factor receptor (EGFR), which has been identified as an important prognostic marker in several other cancer types (Mellon et al, 1995; Fischer-Colbrie et al, 1997; Inada et al, 1999; Kersemaekers et al, 1999; Galizia et al, 2006). The human epidermal growth factor receptor (HER) family of tyrosine kinase receptors consists of four family members, of which the EGFR (EGFR/HER1/erbB1) and HER2 (HER2/NEU/erbB2) are the best

*Correspondence: Dr JE van der Wal;

E-mail: j.e.van.der.wal@path.umcg.nl

Received I March 2010; revised 27 April 2010; accepted 30 April 2010; published online 25 May 2010 known members (Rogers et al, 2005). Binding of the ligands for EGFR, such as TGF- $\alpha$ and EGF, to the extracellular domain of the receptor triggers a dimerisation of the receptors, resulting in autophosphorylation of the tyrosine-rich intracellular domain of EGFR. On activation, the receptors can either homodimerise or heterodimerise with other HER family members, such as HER2. This activated form of the receptor initiates two major downstream signalling pathways, the PI3K/AKT pathway and the Ras/Raf/ MEK/ERK pathway. Activation of these pathways leads to increased proliferation, desensitisation to apoptosis and increased angiogenesis (Yarden and Sliwkowski, 2001; McKay and Morrison, 2007; Jiang and Liu, 2008).

A number of studies reported that overexpression of the EGFR protein (Grandis et al, 1998; Ang et al, 2002; Pivot et al, 2005) is associated with worse prognosis in HNSCC. However, in other studies, the association between the levels of EGFR expression and clinical outcome could not be confirmed (Eriksen et al, 2004; Smid et al, 2006; Fischer et al, 2008). There are various explanations for the differences between these studies, such as various antibodies, protocols and scoring methods. In addition, it has been shown that amplification of the EGFR gene is predictive for clinical outcome in HNSCC (Chung et al, 2006). As EGFR amplification analysis by fluorescent in situ hybridisation (FISH) is more reproducible than 
most immunohistochemical (IHC) staining procedures, this might prove to be a more valuable tool for prognosis than IHC.

The aim of this study was to investigate the prognostic value of EGFR, HER2 and their downstream pathway targets with regard to locoregional control (LRC) in locally advanced HNSCC. For this purpose, tumour specimens of HNSCC patients treated with surgery and postoperative radiotherapy were collected. In addition, we performed in vitro clonogenic survival assays to confirm the hypothesis that followed from the results of the clinical part of our study.

\section{MATERIAL AND METHODS}

\section{Patients and tissues}

This study cohort was composed of consecutive patients diagnosed with HNSCC, uniformly treated with primary surgery and postoperative radiotherapy at the University Medical Center Groningen, The Netherlands, between 1993 and 2003. Clinical and histopathological data of all these patients were collected $(n=198)$ with a follow-up of at least 3 years. Formalin-fixed paraffin-embedded surgically resected tissue of the primary tumour was collected and revised by an experienced pathologist (JEvdW). In 167 cases, sufficient tumour material was available to construct a tissue microarray (TMA). In this study, we included 140 patients for whom IHC stainings for all antigens were assessable. The pre-treatment characteristics of these patients are summarised in Table 1 . In summary, the study cohort mainly consisted of male patients, with a median age of 60 years (range 24-90), with predominantly more advanced T-stage (T3-T4 in $74 \%)$, lymph node metastasis (64\%) and advanced-stage $(84 \%$ stage III and IV) cancers.

All patients underwent surgery of the primary tumour followed by postoperative radiotherapy. In 128 of the cases (91\%), a neck dissection was performed. Postoperative radiotherapy was administered because of positive surgical margins (69\%), lymph node metastases with extranodal spread (36\%) and/or other adverse prognostic factors such as advanced T-stage, multiple lymph node metastases and/or perineural growth. Local recurrence was defined as a recurrence within $2 \mathrm{~cm}$ of the original tumour site and occurring within a 3-year period. Tumours arising more than 3 years after therapy were considered as second primary tumours.

\section{TMA construction}

To construct TMAs, 5- $\mu$ m-thick sections were cut from paraffinembedded formalin-fixed tissue blocks, slides were prepared and a standard haematoxylin and eosin ( $\mathrm{H}$ and $\mathrm{E}$ ) staining was performed. The representative regions in the tumour were marked on the $\mathrm{H}$ and E-stained slides by an experienced pathologist. Three cores of $0.6 \mathrm{~mm}$ diameter were taken from each donor block and put into the recipient paraffin block using the Manual Tissue Arrayer 1 (Beecher Instruments, Silver Spring, MD, USA). Six different normal tissue controls and one oropharyngeal SCC were included on each TMA block to ensure similarity of staining between the slides, orientation on the TMA and recognition of each TMA. Our series of 167 carcinomas was distributed on four TMAs. Sections ( $5 \mu \mathrm{m}$ thick) from each TMA block were cut and the first section was stained with $\mathrm{H}$ and $\mathrm{E}$ to confirm the presence of tumour cells in each core. Using TMAs with three cores with a diameter of $0.6 \mathrm{~mm}$ is considered to be representative for the heterogeneousness of the tumour (Camp et al, 2000; Kallioniemi et al, 2001).

\section{IHC staining}

Tissue microarray sections were deparaffinised in xylene and rehydrated. Antigen retrieval was performed by heating in a
Table I Patient characteristics

\begin{tabular}{|c|c|}
\hline Characteristic & $N(\%)$ \\
\hline Total & $140(100)$ \\
\hline \multicolumn{2}{|l|}{ Age } \\
\hline Median (range), years & $60(24-90)$ \\
\hline \multicolumn{2}{|l|}{ Gender } \\
\hline Female & $46(33)$ \\
\hline Male & $94(67)$ \\
\hline \multicolumn{2}{|l|}{ Primary location } \\
\hline Larynx & $28(20)$ \\
\hline Hypopharynx & $8(6)$ \\
\hline Oropharynx & $25(18)$ \\
\hline Oral cavity & $79(56)$ \\
\hline \multicolumn{2}{|l|}{ T status } \\
\hline TI & $6(4)$ \\
\hline $\mathrm{T} 2$ & $30(22)$ \\
\hline T3 & $34(24)$ \\
\hline T4 & $70(50)$ \\
\hline \multicolumn{2}{|l|}{$N$ status } \\
\hline No & $50(36)$ \\
\hline $\mathrm{N}+$ & $90(64)$ \\
\hline NI & $32(23)$ \\
\hline $\mathrm{N} 2 \mathrm{a}$ & I (I) \\
\hline $\mathrm{N} 2 \mathrm{~b}$ & $42(30)$ \\
\hline $\mathrm{N} 2 \mathrm{c}$ & $13(9)$ \\
\hline N3 & $2(1)$ \\
\hline \multicolumn{2}{|l|}{ Stage } \\
\hline I & I (I) \\
\hline$\|$ & $21(15)$ \\
\hline III & $17(12)$ \\
\hline IV & $101(72)$ \\
\hline \multicolumn{2}{|l|}{ Resection margins } \\
\hline Free & $43(31)$ \\
\hline Not free & $97(69)$ \\
\hline \multicolumn{2}{|l|}{ Extra nodal spread } \\
\hline Yes & $51(36)$ \\
\hline No & $89(64)$ \\
\hline
\end{tabular}

microwave oven for $15 \mathrm{~min}$ in $10 \mathrm{~mm}$ citrate buffer $(\mathrm{pH}=6.0$; for pERK, pAKT, PTEN); in EDTA ( $\mathrm{pH}=8.0$; for $\mathrm{pEGFR})$; in a pressure cooker, three times for $5 \mathrm{~min}$ at $115^{\circ} \mathrm{C}$ (for PI3K); for $30 \mathrm{~min}$ at $95^{\circ} \mathrm{C}$ in a Tris buffer $\left(\mathrm{pH}=9.5\right.$; for EGFR); or for $30 \mathrm{~min}$ at $95^{\circ} \mathrm{C}$ in cell conditioner 1 buffer (Roche Diagnostics/Ventana, Basel, Switzerland) (for HER2).

After antigen retrieval, the endogenous peroxidase was blocked with a $0.3 \%$ peroxide solution. The following primary antibodies were used: EGFR (clone EGFR113, Novocastra (Newcastle upon Tyne, UK), ready to use), pEGFR (clone 1H12, Cell Signalling (Danvers, MA, USA), $1: 200$ ), PTEN (clone 6H2.1, Cascade (Winchester, MA, USA), $1: 100$ ), PI3K p110 (sc-1331, Santa Cruz Biotechnology, Santa Cruz, CA, USA, 1:50), pAKT (ser473) (clone 736E11, Cell Signalling, 1:50), pERK (clone 20G11, Cell Signalling, 1:50) and HER2 (clone CB11, Roche Diagnostics/Ventana, ready to use).

For immunodetection, we used appropriate biotinylated (PTEN, pEGFR, pERK) or horseradish peroxidase (HRP)-conjugated (PI3K) secondary antibody or Envision (Dako, Glostrup, Denmark) (pAKT) followed by appropriate HRP-conjugated tertiary antibody (PI3K) or HRP-conjugated streptavidin (PTEN, pEGFR, pERK) and developed with 3,3'-di-aminobenzidine chromogen solution (Dako) followed by a routine haematoxylin counterstaining. 


\section{Interpretation of IHC}

Staining intensity was semi-quantitatively scored as negative $(0)$, weak positive $(+)$, positive $(++)$ and strong positive $(+++)$ staining. For statistical analysis, any positive staining above background was considered as positive. In addition, the percentage of positive cells was recorded. In case of differences between cores, scores were averaged for statistical analyses.

For the EGFR and HER2 staining, no and incomplete membranous staining were considered negative, and only complete IHC staining of tumour cell membranes above the background was considered positive, independent of the intensity and percentage of positive cells according to the standard Herceptest protocol.

The cases were considered positive for the pEGFR staining if $20 \%$ or more of the cells had membranous, cytoplasmic or nuclear staining; positive for pAKT if $27.5 \%$ or more of the tumour cells had cytoplasmic staining; positive for PTEN when $7.5 \%$ or more of the tumour cells showed a cytoplasmic staining; and positive for PI3K when more than $35 \%$ of the tumour cells had cytoplasmic staining. The cutoff percentages are based on receiver operating characteristic curve analyses for LRR (data not shown) (Zweig and Campbell, 1993). The cases were considered positive for pERK if there was nuclear staining in any of the tumour cells.

Evaluation of immunostaining was performed independently by two observers without information on the clinical data. In case of discrepancies between the observers, cases were reviewed with an experienced pathologist and scored on consensus opinion. Only patients with at least two representative cores were included in the analysis.

\section{Fluorescent in situ hybridisation}

Fluorescent in situ hybridisation analysis was used to determine copy number changes of the EGFR gene. Tissue microarray sections were deparaffinised in xylene and rehydrated, pre-treated in a pressure cooker at $120^{\circ} \mathrm{C}$ in a Tris/EDTA ( $\mathrm{pH} \mathrm{9.0)} \mathrm{buffer,}$ incubated with RNAse A and with $0.1 \%$ pepsin and dehydrated in an ethanol gradient. The DNA was denatured for $12 \mathrm{~min}$ at $80^{\circ} \mathrm{C}$ with the dual-colour EGFR/CEP7 FISH probes (Vysis LSI EGFR SpectrumOrange/CEP 7 SpectrumGreen probe from Abbott, Hoofddorp, The Netherlands) and hybridised at $37^{\circ} \mathrm{C}$ overnight. The sections were incubated in a $0.3 \% \mathrm{NP}-40$ solution at $73^{\circ} \mathrm{C}$ and a $0.1 \%$ NP-40 solution at RT. The sections were dehydrated and covered by a drop of DAPI $(1: 3000)$ in Vectashield (Vector Laboratories, Burlingame, CA, USA) and covered by a coverslip. Images were captured using a Leica DMRA2 fluorescence microscope (Leica Microsystems, Wetzlar, Germany) equipped with a Leica DC $350 \mathrm{~F}$ charge-coupled device camera. Digital images were processed with Leica CW4000 software. Interphase nuclei were examined by eye and the orange and green signals were counted separately in $\sim 20$ nuclei per core. The ratio between EGFR (orange) and centromere 7 signals provides an accurate estimation of copy number differences. A ratio of 1.0 indicates normal copy (or polyploidy of chromosome 7 if $>3$ signals of both probes are observed per nucleus), a ratio $<1$ is loss and $>2$ is gain. Nuclei were considered to contain amplification of EGFR when the number of signals exceeded five (and ratio $>2.5$ ).

\section{Statistical analysis}

Statistical analysis was carried out using the SPSS 14.0.0 software package (SPSS Inc., Chicago, IL, USA). Association between different markers and between markers and clinicopathological characteristics were performed using the $\chi^{2}$-test. The primary end point used in this study was LRC, which was defined by the time from surgery until the first LRR in the case of an event or from the time from surgery until the last follow-up date in the case of no event.
For the univariate and multivariate analysis of clinical outcome, a Cox regression analysis was used. The categorised covariates that showed a trend $(P<0.10)$ in the univariate analysis were put into a back-step multivariate Cox regression analysis. $P$-values $<0.05$ were considered significant. Kaplan-Meier survival curves for LRC were created to illustrate the differences.

\section{Cell culture and transfection}

The Hek293 cell line was cultured in DMEM $\left(1 \mathrm{gl}^{-1}\right.$ glucose) with $10 \%$ fetal bovine serum, $2 \mathrm{~mm}$ ultra-glutamine, penicillin and streptomycin (all purchased from BioWhittaker, Basel, Switzerland). The cells were transfected using Fugene 6 reagent (Roche Allied Sciences, Almere, The Netherlands), as described by the manufacturer, with the empty vector pcDNA3 or the pcDNA3-GFP-PTEN (Addgene plasmid 10759). From one day after transfection on, the cells were cultured in DMEM containing $800 \mu \mathrm{g} \mathrm{ml}^{-1}$ Geneticin (Invitrogen, Carlsbad, CA, USA). Geneticinresistant colonies were separately cultured, and the expression of GFP/PTEN was confirmed using FACS analysis for GFP and immunostaining on western blot using an antibody for PTEN (clone 28H6, 1:500; Santa Cruz Biotechnology).

\section{Clonogenic survival assay to determine radiation response in vitro}

The 96-well plate clonogenic assay based on limiting dilutions was used as described previously in detail (Grenman et al, 1989). The data are based on the average of three independent experiments.

\section{RESULTS}

To assess the expression levels of proteins and phosphoprotein isoforms having an active role in the EGFR pathway in locally advanced HNSCC, IHC was performed on TMAs containing primary tumour material from patients with HNSCC who were all treated with primary surgery and postoperative radiotherapy. In 140 HNSCCs, EGFR was positive in 17 cases (12\%), pEGFR in 56 cases $(40 \%)$, PI3K in 53 cases (38\%), PTEN in 43 cases $(31 \%)$, pAKT in 35 cases $(25 \%)$, pERK in 22 cases (16\%) and HER2 in 11 cases $(8 \%)$ (See examples in Supplementary Figure 1).

\section{PTEN expression is associated with EGFR activation}

To determine whether the activation of the EGFR pathway resulted in the simultaneous activation of other downstream EGFR pathway targets, we performed cross-table analysis between all targets (Table 2). A significant association was found between the expression of EGFR and its activated isoform (pEGFR) $(P=0.027)$ (Table 2a). In addition, pEGFR staining and pERK staining were found to be associated $(P=0.001)$ (Table $2 b)$. The pERK staining showed an inverse relationship with the PI3K staining $(P=0.004)$ (Table $2 \mathrm{c})$ and a positive correlation with PTEN-positive staining $(P=0.028)$ (Table $2 \mathrm{~d})$. Positive staining for PI3K was associated with positive staining for HER2 $(P=0.028) \quad$ (Table $2 \mathrm{e})$. Surprisingly, a positive pAKT staining showed a positive association with PTEN positivity $(P<0.001)$ (Table 2f). Combinations of other stainings were not associated significantly (Supplementary Table 1).

\section{EGFR expression is associated with more advanced-stage tumours}

The correlations between IHC staining and clinicopathological characteristics showed that tumours with a high percentage of pAKT-positive cells had an increased risk on lymph node 
Table 2 Cross-tables showing the correlations between the expression levels of different proteins

\begin{tabular}{cccc}
\hline & \multicolumn{3}{c}{ pEGFR } \\
\cline { 2 - 4 } (a) & Low & High & Total \\
\hline EGFR & & & \\
Low & $78(63)$ & $45(37)$ & 123 \\
High & $6(35)$ & $11(65)$ & 17 \\
Total & 84 & 56 & 140
\end{tabular}

Pearson's $\chi^{2}$-value is $4.9 ; P=0.027$

(b)

\begin{tabular}{lccc}
\cline { 2 - 4 } & Low & High & Total \\
\hline PERK & & & \\
Negative & $78(66)$ & $40(34)$ & 118 \\
Positive & $6(27)$ & $16(72)$ & 22 \\
Total & 84 & 56 & 140
\end{tabular}

Pearson's $\chi^{2}$-value is $11.6 ; P=0.001$

(c)

\begin{tabular}{lccc}
\cline { 3 - 4 } & Low & High & Total \\
\hline PERK & & & \\
Negative & $63(53)$ & $55(47)$ & 1 | 8 \\
Positive & $19(86)$ & $3(14)$ & 22 \\
Total & 82 & 58 & 140
\end{tabular}

Pearson's $\chi^{2}$-value is $8.3 ; P=0.004$

(d)

\begin{tabular}{lccc}
\cline { 2 - 4 } & Low & High & Total \\
\hline Her2 & & & \\
Negative & $79(61)$ & $50(39)$ & 129 \\
Positive & $3(27)$ & $8(73)$ & 11 \\
Total & 82 & 58 & 140
\end{tabular}

Pearson's $\chi^{2}$-value is $4.8 ; P=0.028$

(e)

\begin{tabular}{lccc}
\cline { 2 - 4 } & Low & High & Total \\
\hline PERK & & & \\
Negative & $86(71)$ & $32(29)$ & 118 \\
Positive & $11(50)$ & $11(50)$ & 22 \\
Total & 97 & 43 & 140
\end{tabular}

Pearson's $\chi^{2}$-value is 4.6; $P=0.033$

(f)

\begin{tabular}{lccr}
\cline { 3 - 4 } & Low & High & Total \\
\hline pAKT & & & \\
Low & $81(77)$ & $24(23)$ & 105 \\
High & $16(46)$ & $19(54)$ & 35 \\
Total & 97 & 43 & 140
\end{tabular}

Pearson's $\chi^{2}$-value is 12.2; $P<0.001$

Abbreviations: $\quad E G F R=$ epidermal growth factor receptor; $H E R 2=$ human epidermal growth factor receptor 2; $\mathrm{PAKT}=$ phosphorylated protein kinase $\mathrm{B}$; pEGFR = phospho-EGFR; $\quad$ PERK = phosphorylated extracellular signal-regulated kinase; PI3K = phosphoinositide 3-kinase; PTEN = phosphatase and tensin homologue deleted on chromosome 10.
Table 3 Cross-table EGFR FISH and EGFR $॥$ HC

\begin{tabular}{lrcr}
\hline & \multicolumn{3}{c}{ EGFR FISH } \\
\cline { 2 - 4 } & Normal & Amplification & Total \\
\hline EGFR IHC & & & \\
Low & $101(99)$ & $1(1)$ & 102 \\
High & $3(19)$ & $13(8 \mid)$ & 16 \\
Total & 104 & 14 & 118 \\
\hline
\end{tabular}

Abbreviations: EGFR = epidermal growth factor receptor, FISH = fluorescent in situ hybridisation; $I H C=$ immunohistochemistry. Fischer exact test: $P<0.00$ I. Specificity, 97\%; sensitivity, $93 \%$.

metastases with extranodal spread $(P=0.011)$. High expression of EGFR correlated with lower T-stages $(\mathrm{T} 1-\mathrm{T} 2)\left(\chi^{2}=4.6 ; P=0.032\right)$ and with lower stages (stage I-III) $\left(\chi^{2}=9.2 ; P=0.002\right)$. For the other clinicopathological characteristics, no associations were found with any of the IHC stainings (Supplementary Table 1).

\section{EGFR expression is strongly associated with DNA amplification}

We found high-copy DNA amplification of the EGFR gene in 14 out of the 118 assessable cases (12\%). Immunohistochemical EGFR protein expression was significantly associated with DNA amplification $\left(\chi^{2}=85.22 ; P<0.0001\right)$ as 13 of 16 positive cases showed amplification in contrast to only 1 of 102 EGFR-negative cases. The IHC staining for EGFR was shown to be highly specific (97\%) and highly sensitive (93\%) for EGFR amplification (Table 3). Interestingly, the only case with EGFR amplification that was scored IHC negative (because of lack of membranous staining) showed the strongest cytoplasmic staining among the other cases.

\section{PTEN predicts LRC}

To investigate whether expression of EGFR and its downstream targets were associated with clinical outcome, we performed univariate Cox regression analysis. Expression of PTEN (HR: 2.4; 95\% CI: $1.2-5.0$ ) and pAKT (HR: 2.2; 95\% CI: $1.0-4.6)$ were significantly associated with a worse LRC (Table 4). Locoregional control was also significantly worse in case of lymph node metastases (HR: 5.7; 95\% CI: $2.0-16.3$ ) and in case of extranodal spread (HR: 5.0; 95\% CI: 2.4-10.6). The multivariate Cox regression analysis for LRC showed that PTEN (HR: 2.2; 95\% CI: 1.1-4.6), extranodal spread (HR: $2.7 ; 95 \%$ CI: $1.2-6.5$ ) and the presence of lymph node metastasis (HR: 5.7; 95\% CI: $1.2-27.4$ ) were all independent prognostic factors for LRC. Kaplan-Meier survival analysis showed that patients with PTEN-positive HNSCCs had worse LRC (Figure 1B). Because PTEN and N-status are independent predictors for increased risk for locoregional failure (Table 4), we performed a stratified analysis that revealed that also within the subset of $\mathrm{N}+$ patients, PTEN positivity identified patients with significantly worse LRC $(P<0.001)$ (Figure $1 C)$. In the current study population, the primary anatomical site of the tumour had no significant effect on LRC (data not shown) and no significant interactions were found between the anatomical site of the tumour and IHC staining with respect to LRC, indicating that the effect of PTEN on LRC did not depend on tumour site.

\section{Increased PTEN expression induces increased radioresistance in vitro}

Our data based on IHC suggests that increased PTEN expression might affect the radiosensitivity of tumour cells. To investigate 
Table 4 Cox regression analysis on $\Vdash H C$ and clinical factors, both univariate and multivariate

\begin{tabular}{|c|c|c|}
\hline Cox regression & $\mathbf{N}(\%)$ & $\begin{array}{c}\text { Hazard ratio (HR) for LRR } \\
\text { (95\% Cl; P-value) }\end{array}$ \\
\hline \multicolumn{3}{|l|}{ Univariate } \\
\hline \multicolumn{3}{|l|}{ EGFR } \\
\hline Low & $123(89)$ & । \\
\hline High & $17(11)$ & $0.5(0.1-2.0 ; P=0.32)$ \\
\hline \multicolumn{3}{|l|}{ pEGFR } \\
\hline Low & $84(60)$ & 1 \\
\hline High & $56(40)$ & $1.2(0.6-2.6 ; P=0.58)$ \\
\hline \multicolumn{3}{|l|}{ PI3K } \\
\hline Low & $87(62)$ & 1 \\
\hline High & $53(38)$ & $0.6(0.3-1.4 ; P=0.25)$ \\
\hline \multicolumn{3}{|l|}{ PTEN } \\
\hline Low & $97(69)$ & 1 \\
\hline High & $43(31)$ & $2.4(1.2-5.0 ; P=0.019)^{*}$ \\
\hline \multicolumn{3}{|l|}{ pAKT } \\
\hline Low & $105(75)$ & 1 \\
\hline High & $35(25)$ & $2.2(1.0-4.6 ; P=0.043)^{*}$ \\
\hline \multicolumn{3}{|l|}{ pERK } \\
\hline Negative & II 8 (84) & 1 \\
\hline Positive & $22(16)$ & $1.2(0.5-3.0 ; P=0.65)$ \\
\hline \multicolumn{3}{|l|}{ HER2 } \\
\hline Low & $129(92)$ & | \\
\hline High & II (8) & I $(0.2-4.2 ; P=0.99)$ \\
\hline \multicolumn{3}{|l|}{ Lymph nodes } \\
\hline Negative & $50(36)$ & 1 \\
\hline Positive & $90(64)$ & $5.7(2.0-|6.3 ; P=0.00|)^{*}$ \\
\hline \multicolumn{3}{|l|}{ ENS } \\
\hline No & $89(64)$ & 1 \\
\hline Yes & $51(36)$ & $5(2.4-10.6 ; P<0.001)^{*}$ \\
\hline \multicolumn{3}{|l|}{ Surgical margins } \\
\hline Free & $43(31)$ & 1 \\
\hline Not free & $97(69)$ & $1.4(0.6-3.2 ; P=0.37)$ \\
\hline \multicolumn{3}{|l|}{ Multivariate } \\
\hline \multicolumn{3}{|l|}{ PTEN } \\
\hline Low & $97(69)$ & 1 \\
\hline High & $43(31)$ & $2.2(1.1-4.6 ; P=0.03)^{*}$ \\
\hline \multicolumn{3}{|l|}{ Lymph nodes } \\
\hline Negative (N0) & $50(36)$ & 1 \\
\hline Positive $(\mathrm{N}+)$ & $90(64)$ & $5.7(1.2-27.4 ; P=0.03)^{*}$ \\
\hline \multicolumn{3}{|l|}{ ENS } \\
\hline No & $89(64)$ & 1 \\
\hline Yes & $51(36)$ & $2.7(1.2-6.5 ; P=0.02)^{*}$ \\
\hline
\end{tabular}

Abbreviations: $\mathrm{Cl}=$ confidence interval; EGFR = epidermal growth factor receptor; ENS = extra nodal spread; HER2 = human epidermal growth factor receptor 2; $\mathrm{HC}=$ immunohistochemistry; $\mathrm{pAKT}=$ phosphorylated protein kinase $\mathrm{B} ; \mathrm{pEGFR}=$ phospho-EGFR; $\quad$ EERK $=$ phosphorylated extracellular signal-regulated kinase PI3K = phosphoinositide 3-kinase; PTEN = phosphatase and tensin homologue deleted on chromosome I0. $* P<0.05$.

whether PTEN expression directly affected radiosensivity, we overexpressed the PTEN protein in Hek293 cells (Figure 2B) and tested the sensitivity to radiation in vitro by in vitro clonogenic assays. The PTEN-overexpressing Hek293 cells clearly showed increased radiation resistance compared with the empty vector control (Figure 2A).

\section{DISCUSSION}

The role of EGFR in oncogenesis is widely accepted, as activation of the receptor is known to result in important cancer hallmarks such as proliferation and resistance to apoptosis (Hanahan and Weinberg, 2000). Numerous studies reported on the prognostic value of overexpression of EGFR in many tumour types including HNSCC. The different studies on EGFR in HNSCC are unable to reach consensus on the effect of EGFR overexpression on the clinical outcome (Supplementary Table 2). Reasons for the inconsistency in the IHC could be the different antibodies used, no standard cutoff percentage for dichotomising the data and no consensus on the localisation of staining in the cell. In HNSCC, the percentage of EGFR-positive cases varies from 10 to $90 \%$ (Supplementary Table 2). Compared with these studies, the percentage of EGFR-positive cases in our study is low (12\%). The association between EGFR positivity and low-stage tumours is unusual. We hypothesise that this could be related to the selection of our patient series, that is, only patients who received primary surgery and postoperative radiotherapy were included.

The total number of EGFR-positive cases with either complete or incomplete circumferential immunostaining of the tumour cell membranes was $19 \%$ (27 of 140 cases). However, FISH analysis to determine EGFR gene copy number changes revealed that only complete circumferential immunostaining of the tumour cell membranes using the EGFR113 antibody was a very specific and sensitive marker for amplification of the EGFR gene. As IHC stainings are more routinely performed than FISH analysis in many institutes, the antibody and the protocol that we used could very well be used as a pseudomarker for amplification. The frequency that we found is in good agreement with the previously described amplification frequency of EGFR in HNSCC (Freier et al, 2003; Koynova et al, 2005; Temam et al, 2007).

Recently, both hrHPV positivity and p16 positivity in HNSCC have been reported as very strong prognostic markers for clinical outcome (Chung and Gillison, 2009). In addition, EGFR expression has been inversely associated with the presence of HPV (Kong et al, 2009). To determine whether HPV positivity is related with LRC in our series and associated with EGFR expression, using a semi-quantitative HPV16-/HPV18-specific PCR, as well as the GP5 + $/ 6+$ and CPI/IIg consensus PCR as reported previously (Wisman et al, 2006), only two cases were high-copy HPV16 positive (data not shown). Immunostaining for p16 revealed expression in six cases (3 of 25 oropharyngeal and 3 of 79 oral carcinomas). In the current literature, p16 positivity and hrHPV positivity is mainly reported in carcinomas in the oropharyngeal area (Machado et al, 2010). The relative low number of HPV-positive and p16-positive cases in our series is most probably because of the fact that our study contains only 25 oropharyngeal carcinomas (18\%).

In addition, we observed a significant association between PTEN and pAKT. Phosphatase and tensin homologue deleted on chromosome 10 was originally identified as an antagonist of the AKT pathway, as expression resulted in decreased activation of AKT (Sarbassov et al, 2005). We found that PTEN expression is not only associated with higher pAKT levels but also with nuclear localisation of pERK, both indicators of EGFR pathway activation. These data suggested that the EGFR pathway is more activated in PTEN-positive than in PTEN-negative HNSCC. The positive correlation between PTEN and pAKT has recently been described in ovary cancer (Wang et al, 2005; de Graeff et al, 2008), breast cancer (Panigrahi et al, 2004) and malignant melanoma (Slipicevic et al, 2005). The AKT was reported to become activated by PDK1 (on threonine 308) and by PDK2 (on serine 473), in case AKT is bound to PIP3. Phosphatase and tensin homologue deleted on chromosome 10 dephosphorylates PIP3 to PIP2, by which AKT cannot bind to it anymore and will therefore not be activated by these kinases (Sarbassov et al, 2005). An alternative pathway for 

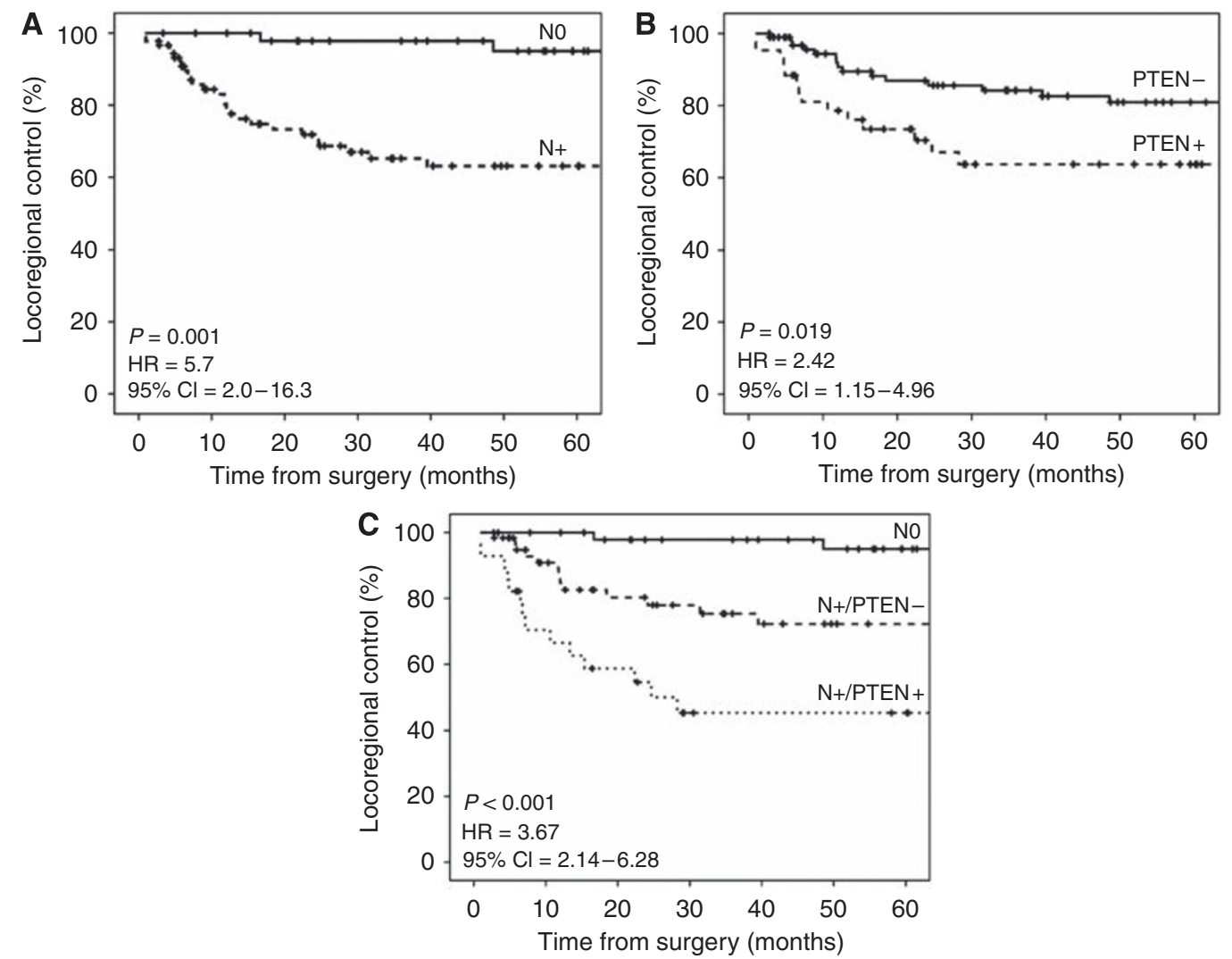

Figure I Kaplan-Meier analysis for locoregional control. (A) Comparing N0 with N+ cases. (B) Comparing phosphatase and tensin homologue deleted on chromosome 10 (PTEN) - with PTEN + cases. (C) Comparing N0 with N+/PTEN - and N+/PTEN+ cases.

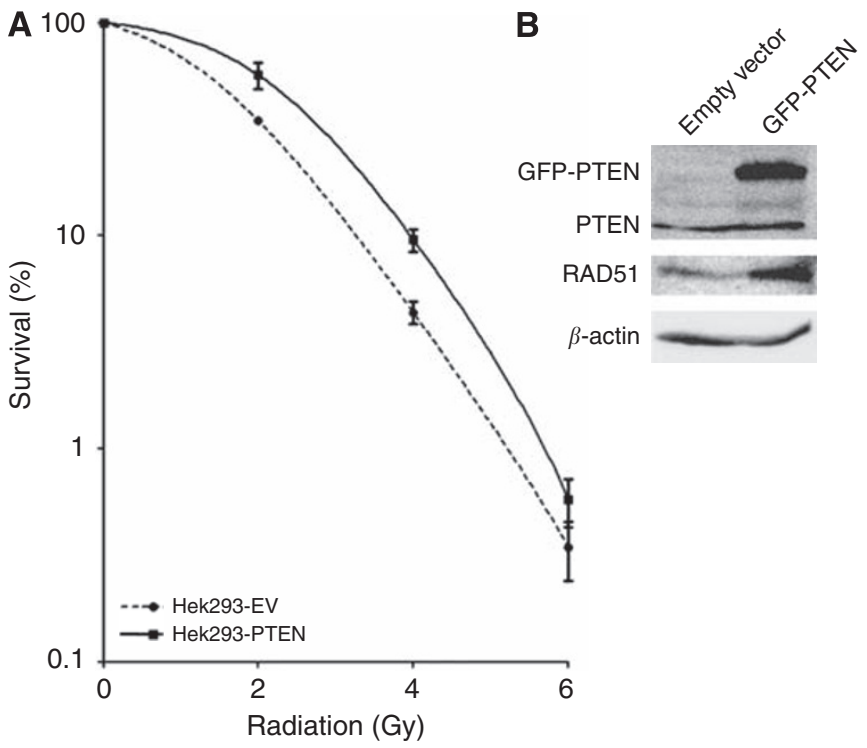

Figure 2 (A) Clonogenic assay, comparing the radiosensitivity of Hek293 cell line stabile transfected with an empty vector or with a plasmid overexpressing phosphatase and tensin homologue deleted on chromosome 10 (PTEN). (B) Western blot analysis for PTEN, RAD5I and $\beta$-actin. Notice that overexpression of PTEN is associated with overexpression of Rad5I in the stabile transfected PTEN cell line.

the phosphorylation of AKT is the integrin pathway. It has been reported that the integrin-linked kinase (ILK) is able to phosphorylate AKT at ser473, independent of the PI3K pathway
(Persad et al, 2000). Tumours that are positive for PTEN seem to have an alternative way of activating AKT and ERK, and the ILK pathway might well be that way.

In our study, both positive PTEN and positive pAKT staining showed a significantly increased risk for LRR. In addition, the presence of extranodal spread and lymph node metastases revealed a significantly increased risk. A multivariate analysis for LRR for these four variables revealed that PTEN status, N-stage and extranodal spread are all independent significant factors, indicating that the PTEN status could have an additive value in determining the prognosis of advanced-stage HNSCC, next to the already used clinical factors of $\mathrm{N}$-stage and extranodal spread.

To support the results of our IHC staining, we performed a clonogenic assay on Hek293 cells, transfected with an overexpression plasmid for PTEN, and compared it with the same cell line transfected with an empty vector. These in vitro data are in line with our findings in the patient series, that is, higher expression of PTEN leads to reduced radiosensitivity. To our knowledge, we are the first to publish this effect of PTEN on radiosensitivity in vitro.

The PTEN/MMAC1 was originally described as a tumour suppressor in a large variety of malignant tumours ( $\mathrm{Li}$ et al, 1997; Panigrahi et al, 2004; Guney et al, 2007). In numerous cancer cell lines and primary tumours, mutations in the PTEN gene and loss of heterozygosity or homozygous deletions have been found (Cairns et al, 1997; Guldberg et al, 1997; Guney et al, 2007). As described earlier, PTEN regulates AKT activity through dephosphorylation of PIP3 (Sarbassov et al, 2005). More recently, two alternative functions for PTEN associated with its nuclear localisation were described (Shen et al, 2007). First, PTEN has a role in maintaining chromosomal stability by forming a complex with the CENP-C protein that binds and stabilises centromeres. 
In addition, PTEN was shown to bind to the promoter region of the double strand break (DSB) repair protein Rad51, resulting in upregulation of Rad51 (Shen et al, 2007; Yin and Shen, 2008). Interestingly, Rad51 expression was also upregulated in our radiation-resistant, PTEN-overexpressing transfectants (Figure 2B), which was in good agreement with the reported study (Shen et al, 2007). The protein Rad51 has been studied extensively and described to repair DSB through homologous recombination (Raderschall et al, 2002; Shen et al, 2007; Klein, 2008). The Rad51 $1^{-l-}$ mice are not viable (Lim and Hasty, 1996) and DT40 Rad51 knockdown cells have been reported to accumulate chromosomal breaks during the replication and arrest in the G2/M phase of the cell cycle (Sonoda et al, 1998). Furthermore, overexpression of the Rad51 protein has been reported to increase the radioresistance of cell lines (Lundin et al, 2003). The association between PTEN overexpression and both worse LRC in patients as well as radioresistance in cell lines (this study) might therefore be explained through the overexpression of Rad51.

In conclusion, PTEN-positive HNSCC have a worse LRC when treated with primary surgery and postoperative radiotherapy. In these tumours, the AKT pathway is more frequently activated than in PTEN-negative tumours. A PTEN-overexpressing HEK293 cell line is more radiation resistant than the empty vectortransfected control cells, and in this overexpressing cell line RAD51 is upregulated. We therefore propose that the mechanism by which PTEN-positive HNSCC have a worse LRC is through upregulation of RAD51, leading to better DSB repair.

Supplementary Information accompanies the paper on British Journal of Cancer website (http://www.nature.com/bjc)

\section{REFERENCES}

Ang KK, Berkey BA, Tu X, Zhang HZ, Katz R, Hammond EH, Fu KK, Milas L (2002) Impact of epidermal growth factor receptor expression on survival and pattern of relapse in patients with advanced head and neck carcinoma. Cancer Res 62(24): 7350-7356

Cairns P, Okami K, Halachmi S, Halachmi N, Esteller M, Herman JG, Jen J, Isaacs WB, Bova GS, Sidransky D (1997) Frequent inactivation of PTEN/MMAC1 in primary prostate cancer. Cancer Res 57(22): $4997-5000$

Camp RL, Charette LA, Rimm DL (2000) Validation of tissue microarray technology in breast carcinoma. Lab Invest 80(12): 1943-1949

Chung $\mathrm{CH}$, Ely K, McGavran L, Varella-Garcia M, Parker J, Parker N, Jarrett C, Carter J, Murphy BA, Netterville J, Burkey BB, Sinard R, Cmelak A, Levy S, Yarbrough WG, Slebos RJ, Hirsch FR (2006) Increased epidermal growth factor receptor gene copy number is associated with poor prognosis in head and neck squamous cell carcinomas. J Clin Oncol 24(25): $4170-4176$

Chung CH, Gillison ML (2009) Human papillomavirus in head and neck cancer: its role in pathogenesis and clinical implications. Clin Cancer Res 15(22): $6758-6762$

de Graeff P, Crijns AP, Ten Hoor KA, Klip HG, Hollema H, Oien K, Bartlett JM, Wisman GB, de Bock GH, de Vries EG, de Jong S, van der Zee AG (2008) The ErbB signalling pathway: protein expression and prognostic value in epithelial ovarian cancer. Br J Cancer 99(2): 341 - 349

Eriksen JG, Steiniche T, Askaa J, Alsner J, Overgaard J (2004) The prognostic value of epidermal growth factor receptor is related to tumor differentiation and the overall treatment time of radiotherapy in squamous cell carcinomas of the head and neck. Int J Radiat Oncol Biol Phys 58(2): $561-566$

Fischer C, Zlobec I, Stockli E, Probst S, Storck C, Tornillo L, Lugli A, Wolfensberger M, Terracciano L (2008) Is immunohistochemical epidermal growth factor receptor expression overestimated as a prognostic factor in head-neck squamous cell carcinoma? A retrospective analysis based on a tissue microarray of 365 carcinomas. Hum Pathol 39(10): $1527-1534$

Fischer-Colbrie J, Witt A, Heinzl H, Speiser P, Czerwenka K, Sevelda P, Zeillinger R (1997) EGFR and steroid receptors in ovarian carcinoma: comparison with prognostic parameters and outcome of patients. Anticancer Res 17(1B): 613-619

Freier K, Joos S, Flechtenmacher C, Devens F, Benner A, Bosch FX, Lichter P, Hofele C (2003) Tissue microarray analysis reveals site-specific prevalence of oncogene amplifications in head and neck squamous cell carcinoma. Cancer Res 63(6): 1179-1182

Galizia G, Lieto E, Ferraraccio F, De Vita F, Castellano P, Orditura M, Imperatore V, La Mura A, La Manna G, Pinto M, Catalano G, Pignatelli C, Ciardiello F (2006) Prognostic significance of epidermal growth factor receptor expression in colon cancer patients undergoing curative surgery. Ann Surg Oncol 13(6): 823-835

Grandis JR, Melhem MF, Gooding WE, Day R, Holst VA, Wagener MM, Drenning SD, Tweardy DJ (1998) Levels of TGF-alpha and EGFR protein in head and neck squamous cell carcinoma and patient survival. J Natl Cancer Inst 90(11): 824-832

Grenman R, Burk D, Virolainen E, Buick RN, Church J, Schwartz DR, Carey TE (1989) Clonogenic cell assay for anchorage-dependent squamous carcinoma cell lines using limiting dilution. Int $\mathrm{J}$ Cancer 44(1): $131-136$

Guldberg P, thor Straten P, Birck A, Ahrenkiel V, Kirkin AF, Zeuthen J (1997) Disruption of the MMAC1/PTEN gene by deletion or mutation is a frequent event in malignant melanoma. Cancer Res 57(17): 3660 - 3663

Guney K, Ozbilim G, Derin AT, Cetin S (2007) Expression of PTEN protein in patients with laryngeal squamous cell carcinoma. Auris Nasus Larynx 34(4): $481-486$

Hanahan D, Weinberg RA (2000) The hallmarks of cancer. Cell 100(1): $57-70$

Inada S, Koto T, Futami K, Arima S, Iwashita A (1999) Evaluation of malignancy and the prognosis of esophageal cancer based on an immunohistochemical study (p53, E-cadherin, epidermal growth factor receptor). Surg Today 29(6): $493-503$

Jiang BH, Liu LZ (2008) PI3K/PTEN signaling in tumorigenesis and angiogenesis. Biochim Biophys Acta 1784(1): 150-158

Kallioniemi OP, Wagner U, Kononen J, Sauter G (2001) Tissue microarray technology for high-throughput molecular profiling of cancer. $\mathrm{Hum} \mathrm{Mol}$ Genet 10(7): $657-662$

Kersemaekers AM, Fleuren GJ, Kenter GG, Van den Broek LJ, Uljee SM, Hermans J, Van de Vijver MJ (1999) Oncogene alterations in carcinomas of the uterine cervix: overexpression of the epidermal growth factor receptor is associated with poor prognosis. Clin Cancer Res 5(3): $577-586$

Klein HL (2008) The consequences of Rad51 overexpression for normal and tumor cells. DNA Repair (Amst) 7(5): 686-693

Kong CS, Narasimhan B, Cao H, Kwok S, Erickson JP, Koong A, Pourmand N, Le QT (2009) The relationship between human papillomavirus status and other molecular prognostic markers in head and neck squamous cell carcinomas. Int J Radiat Oncol Biol Phys 74(2): 553-561

Koynova DK, Tsenova VS, Jankova RS, Gurov PB, Toncheva DI (2005) Tissue microarray analysis of EGFR and HER2 oncogene copy number alterations in squamous cell carcinoma of the larynx. J Cancer Res Clin Oncol 131(3): 199-203

Le Tourneau C, Jung GM, Borel C, Bronner G, Flesch H, Velten M (2008) Prognostic factors of survival in head and neck cancer patients treated with surgery and postoperative radiation therapy. Acta Otolaryngol 128(6): $706-712$

Li J, Yen C, Liaw D, Podsypanina K, Bose S, Wang SI, Puc J, Miliaresis C, Rodgers L, McCombie R, Bigner SH, Giovanella BC, Ittmann M, Tycko B, Hibshoosh H, Wigler MH, Parsons R (1997) PTEN, a putative protein tyrosine phosphatase gene mutated in human brain, breast, and prostate cancer. Science 275(5308): $1943-1947$

Lim DS, Hasty P (1996) A mutation in mouse rad51 results in an early embryonic lethal that is suppressed by a mutation in p53. Mol Cell Biol 16(12): $7133-7143$

Lundin C, Schultz N, Arnaudeau C, Mohindra A, Hansen LT, Helleday T (2003) RAD51 is involved in repair of damage associated with DNA replication in mammalian cells. J Mol Biol 328(3): $521-535$ 
Machado J, Reis PP, Zhang T, Simpson C, Xu W, Perez-Ordonez B, Goldstein DP, Brown DH, Gilbert RW, Gullane PJ, Irish JC, Kamel-Reid S (2010) Low prevalence of Human Papillomavirus in oral cavity carcinomas. Head Neck Oncol 2: 6

McKay MM, Morrison DK (2007) Integrating signals from RTKs to ERK/MAPK. Oncogene 26(22): 3113-3121

Mellon K, Wright C, Kelly P, Horne CH, Neal DE (1995) Long-term outcome related to epidermal growth factor receptor status in bladder cancer. J Urol 153(3 Part 2): 919-925

Panigrahi AR, Pinder SE, Chan SY, Paish EC, Robertson JF, Ellis IO (2004) The role of PTEN and its signalling pathways, including AKT, in breast cancer; an assessment of relationships with other prognostic factors and with outcome. J Pathol 204(1): $93-100$

Partridge M, Gaballah K, Huang X (2005) Molecular markers for diagnosis and prognosis. Cancer Metastasis Rev 24(1): 71-85

Persad S, Attwell S, Gray V, Delcommenne M, Troussard A, Sanghera J, Dedhar S (2000) Inhibition of integrin-linked kinase (ILK) suppresses activation of protein kinase B/Akt and induces cell cycle arrest and apoptosis of PTEN-mutant prostate cancer cells. Proc Natl Acad Sci USA 97(7): $3207-3212$

Pivot X, Magne N, Guardiola E, Poissonnet G, Dassonville O, Francoual M, Formento JL, Bensadoun RJ, Demard F, Schneider M, Milano G (2005) Prognostic impact of the epidermal growth factor receptor levels for patients with larynx and hypopharynx cancer. Oral Oncol 41(3): $320-327$

Raderschall E, Stout K, Freier S, Suckow V, Schweiger S, Haaf T (2002) Elevated levels of Rad51 recombination protein in tumor cells. Cancer Res 62(1): 219-225

Rogers SJ, Harrington KJ, Rhys-Evans P, Charoenrat P, Eccles SA (2005) Biological significance of c-erbB family oncogenes in head and neck cancer. Cancer Metastasis Rev 24(1): 47-69

Sarbassov DD, Guertin DA, Ali SM, Sabatini DM (2005) Phosphorylation and regulation of $\mathrm{Akt} / \mathrm{PKB}$ by the rictor-mTOR complex. Science 307(5712): $1098-1101$
Shen WH, Balajee AS, Wang J, Wu H, Eng C, Pandolfi PP, Yin Y (2007) Essential role for nuclear PTEN in maintaining chromosomal integrity. Cell 128(1): $157-170$

Slipicevic A, Holm R, Nguyen MT, Bohler PJ, Davidson B, Florenes VA (2005) Expression of activated Akt and PTEN in malignant melanomas: relationship with clinical outcome. Am J Clin Pathol 124(4): 528-536

Smid EJ, Stoter TR, Bloemena E, Lafleur MV, Leemans CR, van der Waal I, Slotman BJ, Langendijk JA (2006) The importance of immunohistochemical expression of EGFr in squamous cell carcinoma of the oral cavity treated with surgery and postoperative radiotherapy. Int J Radiat Oncol Biol Phys 65(5): 1323-1329

Sonoda E, Sasaki MS, Buerstedde JM, Bezzubova O, Shinohara A, Ogawa H, Takata M, Yamaguchi-Iwai Y, Takeda S (1998) Rad51-deficient vertebrate cells accumulate chromosomal breaks prior to cell death. EMBO J 17(2): $598-608$

Temam S, Kawaguchi H, El Naggar AK, Jelinek J, Tang H, Liu DD, Lang W, Issa JP, Lee JJ, Mao L (2007) Epidermal growth factor receptor copy number alterations correlate with poor clinical outcome in patients with head and neck squamous cancer. J Clin Oncol 25(16): 2164-2170

Wang Y, Kristensen GB, Helland A, Nesland JM, Borresen-Dale AL, Holm R (2005) Protein expression and prognostic value of genes in the erb-b signaling pathway in advanced ovarian carcinomas. Am J Clin Pathol 124(3): $392-401$

Wisman GB, Nijhuis ER, Hoque MO, Reesink-Peters N, Koning AJ, Volders HH, Buikema HJ, Boezen HM, Hollema H, Schuuring E, Sidransky D, van der Zee AG (2006) Assessment of gene promoter hypermethylation for detection of cervical neoplasia. Int J Cancer 119(8): 1908-1914

Yarden Y, Sliwkowski MX (2001) Untangling the ErbB signalling network. Nat Rev Mol Cell Biol 2(2): 127-137

Yin Y, Shen WH (2008) PTEN: a new guardian of the genome. Oncogene 27(41): $5443-5453$

Zweig MH, Campbell G (1993) Receiver-operating characteristic (ROC) plots: a fundamental evaluation tool in clinical medicine. Clin Chem 39(4): $561-577$ 